\title{
Studies on dielectric hysteresis of ferroelectric potassium vanadate and lithium vanadate doped with $\mathrm{Gd}_{2} \mathrm{O}_{3}$
}

\author{
A P KASHID, V V PATIL ${ }^{1}$ and S H CHAVAN ${ }^{2 *}$ \\ Department of Physics, Warana Mahavidyalaya, Warananagar 416113, India \\ 'Main Rajaram Jr. College, Kolhapur 416002 , India \\ ${ }^{2}$ Department of Physics, Shivaji University, Kolhapur 416004 , India \\ MS received 30 January 1989; revised 1 June 1989
}

\begin{abstract}
The dielectric hysteresis property of undoped and $\mathrm{Gd}_{2} \mathrm{O}_{3}$-doped potassium vanadate and lithium vanadate has been investigated in the temperature range covering their transition points. The hysteresis loop method has been used for coercive field measurements. The coercive field of $\mathrm{Gd}_{2} \mathrm{O}_{3}$-doped $\mathrm{KVO}_{3}$ and $\mathrm{LiVO}_{3}$ increases for 0.025 , 0.05 , and $0.1 \mathrm{~mol} \%$, however, it decreases for $0.5,1$ and $3 \mathrm{~mol} \%$ of $\mathrm{Gd}_{2} \mathrm{O}_{3}$. It was found that the Curie temperatures of $\mathrm{KVO}_{3}$ and $\mathrm{LiVO}_{3}$ remain the same for various concentrations of $\mathrm{Gd}_{2} \mathrm{O}_{3}$.
\end{abstract}

Keywords. Ferroelectrics; Curie temperature: hysteresis; coercive field.

\section{Introduction}

The basic criterion for the identification of a ferroelectric material is the presence of the hysteresis loop. The hysteresis loop observations enable the measurement of the spontaneous polarization and coercive fields of ferroelectrics. The coercive field of a ferroelectric crystal is defined as the external field which requires discontinuous transition from a metastable state to a stable state through domain reversal. The coercive field is also the field for which the probability of nucleating antiparallel domains start increasing very rapidly (Merz 1954; Janovec 1958). A theoretical treatment based on the assumption that the coercive field is determined by the velocity of the forward growth of the domains was given by Abe (1960).

The aim of our present work is to study the dielectric hysteresis of $\mathrm{KVO}_{3}$ and $\mathrm{LiVO}_{3}$ doped with $\mathrm{Gd}_{2} \mathrm{O}_{3}$ and the variation of coercive field with temperature.

\section{Experimental}

Crystalline vanadates grown from a stoichiometric mixture of alkali metal carbonates and vanadium pentaoxide (purity $>99 \%$ ) were heated slowly inside a globar furnace up to $750^{\circ} \mathrm{C}$ for $4 \mathrm{~h}$ and the melt then furnace-cooled. $\mathrm{Gd}_{2} \mathrm{O}_{3}$ was used as an additive (purity $99.9 \%$, procured from John Baker Inc, Colorado, USA). The samples were prepared by taking $\mathrm{Gd}_{2} \mathrm{O}_{3}$ in quantities ranging from 0.025 to $3 \mathrm{~mol} \%$ in $\mathrm{KVO}_{3}$ and $\mathrm{LiVO}_{3}$. Every batch was dry-mixed and then wet with ethyl alcohol and thoroughly mixed. After the alcohol was completely evaporated, each batch of the mixtures was heated in a platinum crucible at $950^{\circ} \mathrm{C}$ for $5 \mathrm{~h}$. The samples prepared were confirmed by scanning them on an X-ray diffractometer. Pellets of these samples, prepared under $5 \mathrm{t}$ pressure, and about $0.1 \mathrm{~cm}$ thick and of $1 \mathrm{~cm}$ diameter were sintered on platinum foil at $500^{\circ} \mathrm{C}$ for $3 \mathrm{~h}$. The pellets were

*For correspondence. 
polished and the two opposite surfaces coated with thin layers of air-drying silver paste for good electrical contact.

The experimental set-up consisted of an electrically heated furnace, a digital microvoltmeter and a modified form of the Sawyer and Tower (1930) circuit. The pellets of $\mathrm{KVO}_{3}$ and $\mathrm{LiVO}_{3}$ doped with $\mathrm{Gd}_{2} \mathrm{O}_{3}(0 \cdot 025-3 \mathrm{~mol} \%)$ were heated slowly inside a furnace and the hysteresis loop was observed on the screen of an oscilloscope. The field amplitude across the pellet was $1 \mathrm{kV} / \mathrm{cm}$ and frequency $50 \mathrm{~Hz}$. The half-width hysteresis loop enables the measurement of the coercive field at various temperatures.

\section{Results and discussion}

The temperature-dependence of the coercive field for undoped $\mathrm{KVO}_{3}$ and $\mathrm{LiVO}_{3}$, and for those doped with different concentrations $(0.025,0.05,0 \cdot 1,0.5,1$ and $3 \mathrm{~mol} \%$ ) of $\mathrm{Gd}_{2} \mathrm{O}_{3}$ is shown in figures 1 and 2 respectively. From these figures it is clear that the coercive field strongly depends upon the temperature. It decreases with increasing temperature and vanishes at a certain temperature, indicating the transition temperature of the ferroelectric material. The Curie temperatures investigated by the hysteresis loop method of $\mathrm{KVO}_{3}$ and $\mathrm{LiVO}_{3}$ are found to be 320 and $405^{\circ} \mathrm{C}$ respectively, in good agreement with those reported by Chavan and Suryavanshi (1985) and Patil et al (1988). The addition of $\mathrm{Gd}_{2} \mathrm{O}_{3}$ to $\mathrm{KVO}_{3}$ and

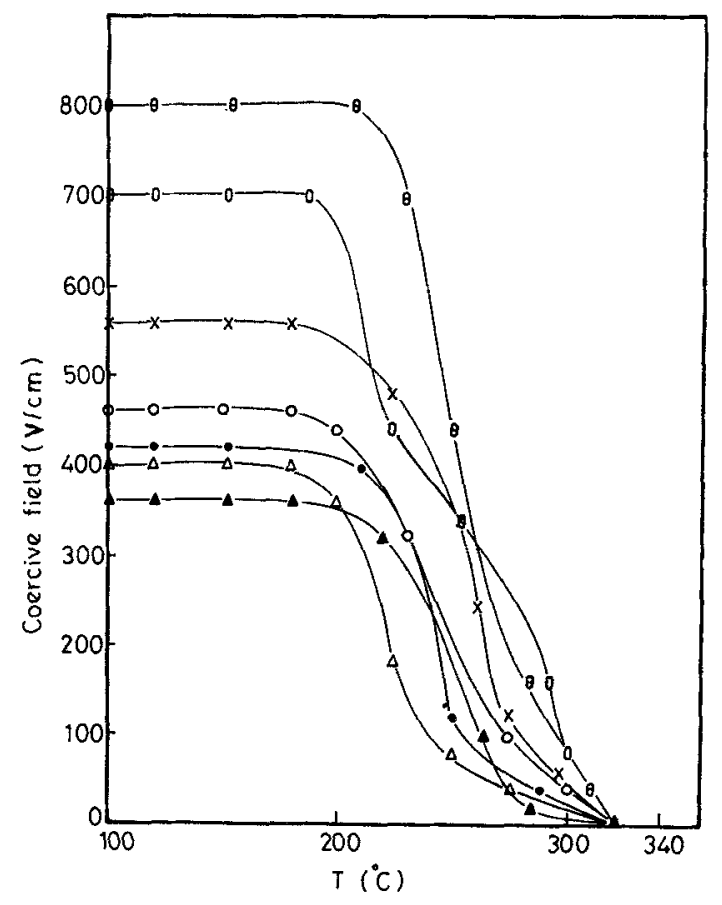

Figure 1. Coercive field of $\mathrm{KVO}_{3}$ measured with a field amplitude of $1 \mathrm{kV} / \mathrm{cm}$ at $50 \mathrm{~Hz}$ as a function of temperature for different $\mathrm{Gd}_{2} \mathrm{O}_{3}$ additions $-\mathrm{O} 0, \times 0.025,00.05,80.1$, $0.5, \Delta 1, \Delta 3 \mathrm{~mol} \%$. 


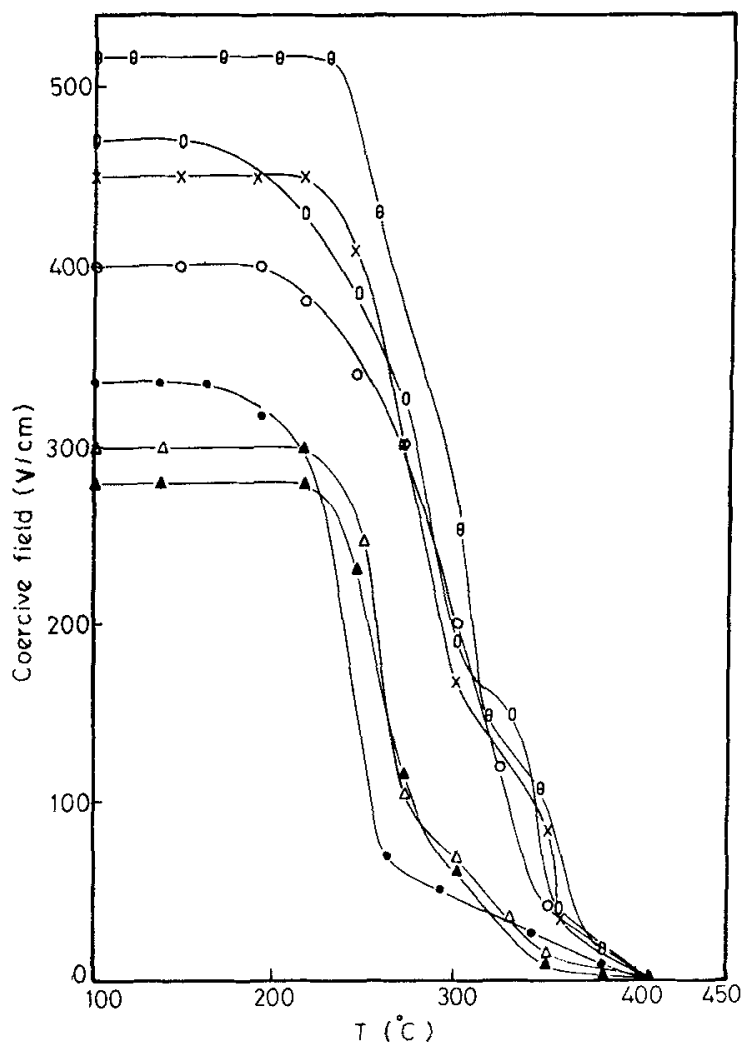

Figure 2. Coercive field of $\mathrm{LiVO}_{3}$ measured with a field amplitude of $1 \mathrm{kV} / \mathrm{cm}$ at $50 \mathrm{~Hz}$ as a function of temperature for different $\mathrm{Gd}_{2} \mathrm{O}_{3}$ additions $-\mathrm{O} 0, \times 0.025,00.05, \theta 0.1$, $0.5, \triangle 1, \Delta 3 \mathrm{~mol} \%$.

$\mathrm{LiVO}_{3}$ shows no change in the Curie temperature in agreement with the results obtained by Yamaji et al (1977) and Issa et al (1984).

It is also observed (figures 1 and 2) that the coercive field depends on doping concentrations. The peak values of the coercive field for samples containing 0.025 , $0.05,0.1 \mathrm{~mol} \% \mathrm{Gd}_{2} \mathrm{O}_{3}$ increase with respect to the undoped ceramics, $\mathrm{KVO}_{3}$ and $\mathrm{LiVO}_{3}$, and decrease for the samples containing $0 \cdot 5,1$ and $3 \mathrm{~mol} \%$ of $\mathrm{Gd}_{2} \mathrm{O}_{3}$. The maximum values of the coercive field for $\mathrm{KVO}_{3}$ and $\mathrm{LiVO}_{3}$ doped with $\mathrm{Gd}_{2} \mathrm{O}_{3}$ are shown in tables 1 and 2 .

Tables 1 and 2 reveal that the value of the coercive field is maximum at $0.1 \mathrm{~mol} \%$ and minimum at $3 \mathrm{~mol} \%$ doping of $\mathrm{Gd}_{2} \mathrm{O}_{3}$ in $\mathrm{KVO}_{3}$ and $\mathrm{LiVO}_{3}$. This can be studied from the pronounced increase of density on addition of $\mathrm{Gd}_{2} \mathrm{O}_{3}$. The maximum densification is observed at $0.1 \mathrm{~mol} \%$ doping of $\mathrm{Gd}_{2} \mathrm{O}_{3}$. Thus in this investigation the dielectric saturation states are attained at $0.1 \mathrm{~mol} \% \mathrm{Gd}_{2} \mathrm{O}_{3}$ addition, which may represent the solubility limit of $\mathrm{Gd}_{2} \mathrm{O}_{3}$ in $\mathrm{KVO}_{3}$ and $\mathrm{LiVO}_{3}$ lattices.

\section{Conclusions}

From the experimental observations it is concluded that (i) the Curie temperatures 
Table 1. Maximum values of coercive field and densities of $\mathrm{KVO}_{3}$.

\begin{tabular}{lcc}
\hline $\begin{array}{l}\mathrm{Gd}_{2} \mathrm{O}_{3} \text { content } \\
(\mathrm{mol} \%)\end{array}$ & $\begin{array}{c}\text { Coercive field } \\
(\mathrm{V} / \mathrm{cm})\end{array}$ & $\begin{array}{c}\text { Density } \\
\left(\mathrm{g} / \mathrm{cm}^{3}\right)\end{array}$ \\
\hline $0($ Pure $)$ & 460 & $2 \cdot 20$ \\
0.025 & 560 & $2 \cdot 34$ \\
0.05 & 700 & $2 \cdot 41$ \\
0.1 & 800 & $2 \cdot 62$ \\
0.5 & 420 & $2 \cdot 61$ \\
1 & 400 & $2 \cdot 61$ \\
3 & 360 & 2.60 \\
\hline
\end{tabular}

Table 2. Maximum values of coercive field and densities of $\mathrm{LiVO}_{3}$.

\begin{tabular}{lcc}
\hline $\begin{array}{l}\mathrm{Gd}_{2} \mathrm{O}_{3} \text { content } \\
(\mathrm{mol} \%)\end{array}$ & $\begin{array}{c}\text { Coercive field } \\
(\mathrm{V} / \mathrm{cm})\end{array}$ & $\begin{array}{c}\text { Density } \\
\left(\mathrm{g} / \mathrm{cm}^{3}\right)\end{array}$ \\
\hline 0 (Pure) & 400 & $2 \cdot 32$ \\
0.025 & 450 & $2 \cdot 44$ \\
0.05 & 470 & $2 \cdot 55$ \\
0.1 & 515 & $2 \cdot 71$ \\
0.5 & 335 & $2 \cdot 69$ \\
1 & 300 & $2 \cdot 68$ \\
3 & 280 & 2.68 \\
\hline
\end{tabular}

of $\mathrm{KVO}_{3}$ and $\mathrm{LiVO}_{3}$ remain the same for various doping concentrations of $\mathrm{Gd}_{2} \mathrm{O}_{3}$, (ii) the coercive field depends on the temperature; it vanishes at $320^{\circ} \mathrm{C}$ for $\mathrm{KVO}_{3}$ and at $405^{\circ} \mathrm{C}$ for $\mathrm{LiVO}_{3}$, indicating their transition temperatures, (iii) the coercive field increases with increasing doping concentrations of up to $0.1 \mathrm{~mol} \%$ and then decreases for higher doping concentrations $(0.5,1$ and $3 \mathrm{~mol} \%)$.

\section{References}

Abe R 1960 J. Phys. Soc. Jpn. 15795

Chavan S H and Suryavanshi S G 1985 Indian J. Phys. A59 555

Issa M A A, Molokhia N M and Nasser S A $1984 J$. Phys. D17 571

Janovec V 1958 Czech. J. Phys. 83

Merz W J 1954 Phys. Rev. 95690

Patil T A, Jamadar V M and Chavan S H 1988 Indian J. Phys. A62 341

Sawyer C B and Tower C H 1930 Phys. Rev. 35269

Yamaji A, Enomoto Y, Kinoshita K and Murakami T 1977 J. Am. Ceram. Soc. 6097 